\title{
Multi-level characterization of steel reinforced mortars for strengthening of masonry structures
}

\section{Bahman Ghiassi*1 $^{* 1}$, Daniel V. Oliveira ${ }^{2}$, Vera Marques ${ }^{3}$, Edgar Soares ${ }^{4}$, Hamid Maljaee ${ }^{5}$ ABSTRACT}

Textile Reinforced Mortars (TRMs) have received extensive attention for externally bonded reinforcement of historical and masonry structures. Despite this recent attention, the available information on the test methods and mechanical performance of TRMs at different scales are limited. Extensive experimental results are still necessary for development of design formulas and application guidelines. This paper presents a multi-level experimental investigation on the performance of Steel Reinforced Grouts (SRGs) as a common TRM type. The focus is not only on the mechanical characterization but also the test methods and practical challenges. The tests include materials characterization, fiber-to-mortar bond characterization, tensile tests on TRM composite, and TRM-to-masonry bond characterization tests. The tests are performed on three different SRG systems made of pozzolanic lime-based and geopolymeric-based mortars as sustainable matrices for strengthening and restoration applications.

Keywords: Textile Reinforced Mortar; Masonry; EBR Strengthening; Geopolymer mortar; Limebased mortar; Experimental characterization;

\footnotetext{
${ }^{1}$ Post-doctoral research associate, ISISE, University of Minho, Department of Civil Engineering, Azurém, 4800-058 Guimarães, Portugal. Phone: +351 253510 499, fax: +351 253510 217, E-mail: bahmanghiassi@gmail.com

${ }^{2}$ Associate Professor, ISISE, University of Minho, Department of Civil Engineering, Azurém, 4800-058 Guimarães, Portugal. Phone: +351253 510 247, fax: +351 253510 217, E-mail: danvco@ civil.uminho.pt

3 Msc, ISISE, University of Minho, Department of Civil Engineering, Azurém, 4800-058 Guimarães, Portugal. Phone: +351 253510247 , fax: +351253 510 217, E-mail: a58570@alumni.uminho.pt

${ }^{4} \mathrm{PhD}$ student, ISISE, University of Minho, Department of Civil Engineering, Azurém, 4800-058 Guimarães, Portugal. Phone: +351253510499 , fax: +351 253510217 , E-mail: id5261@alunos.uminho.pt

5 PhD student, ISISE, University of Minho, Department of Civil Engineering, Azurém, 4800-058 Guimarães, Portugal. Phone: +351 253 510499 , fax: +351 253510 217, E-mail: h.maljaee.civil@gmail.com
} 


\section{Introduction}

Textile Reinforced Mortars (TRMs) have recently received extensive attention as a suitable replacement of conventional Fiber Reinforced Polymers (FRPs) for externally bonded reinforcement of masonry structures. TRMs provide several advantages in comparison to FRPs including physical and mechanical compatibility with the masonry substrate, acceptable performance under high temperatures and fire exposure, and low installation costs [1].

TRM composites are made of continuous fibers embedded in an inorganic (cementitious or limebased) matrix. Cementitious mortars are usually used for application to new buildings or concrete structures and lime-based mortars are suggested for application to existing masonry and historical structures [1]. Several types of fibers including steel, glass, basalt and polyparaphenylene benzobisoxazole (PBO) are available in the market as the reinforcement. The large variety of available fibers and mortar types leads to a wide range of TRMs with different mechanical and physical properties. This has made the proposal of a unified design and application procedure a challenging task.

Differently from cementitious-based TRMs that have been used for strengthening of RC structures for several years, see e.g. [2,3], application of TRMs for masonry and historical structures is rather recent. Fundamental information about short-term and long-term mechanical properties are still not available, and suitable design and analysis methods do not exist [1,4]. Standard test methods and constitutive models are also not available yet. Investigation of the mechanical behavior (tensile and bond performance), e.g. [8-10], and their effectiveness in improving the performance of masonry components, e.g. [5-7], have been the subject of some recent studies. The effectiveness of this strengthening technique is highly dependent on the mortar-to-substrate bond behavior, the 
fiber-to-mortar bond behavior, and mechanical properties of the fibers and the matrix [3]. A deep understanding of these mechanisms is thus critical and is the main objective of this study. Among the large variety of available TRMs for application to masonry structures, Steel Reinforced Grouts (SRGs) are of particular interest due to their mechanical properties and bond efficiency. Application of SRGs on structural components has proved their efficiency in performance improvement, see e.g. [11-13]. The available results are still very limited at the material and composite level and mostly focused on the tensile or TRM-to-masonry bond behavior, see e.g. $[10,14]$. Further investigations at different levels/scales are necessary for deep understanding of the mechanics of these systems and development of unified design methods.

This paper presents a multi-level experimental investigation on the performance of SRG composites applied to masonry bricks. Three SRG types composed of a commercial steel fiber embedded in different mortars (including two commercially available lime-based mortar and a laboratory-made geopolymeric-based mortar) are investigated. The tests include materials mechanical characterization, single fiber-to-mortar bond pull-out tests, tensile tests on SRG coupons, and SRG-to-masonry bond characterization tests. A detailed discussion on the test methods and procedures, the encountered challenges, and the obtained results are presented throughout the paper.

\section{Experimental program}

The experimental campaign was aimed at multi-level mechanical characterization of three SRG types used for strengthening of masonry and historical structures. The detailed description of the specimens and test methods are given in this section. 


\subsection{Materials}

Materials consisted of an extruded solid clay brick with dimensions of $200 \times 100 \times 50 \mathrm{~mm}^{3}$ as the substrate. The strengthening materials were composed of a commercial galvanized (zinc coated) carbon steel textile made of cords as the reinforcement and three mortar types as the matrix. According to the technical datasheets provided by the manufacturer, the steel cords were made of five twisted individual wire filaments (each cord having an effective area of $0.538 \mathrm{~mm}^{2}$ and weight

of $670 \mathrm{~g} / \mathrm{m}^{2}$ ). The selected mortars were two commercially available pozzolanic lime-based mortars with similar mechanical properties (denoted as A and B) and a geopolymeric-based mortar with a low mechanical properties (denoted as G). Mortar A (MAPEI Planitop HDM) was a two component mortar prepared by mixing the components with an electric mixer until reaching a consistent paste as proposed in the technical datasheets. Mortar B (BASF ALBARIA STRUTTURA) was a one component mortar prepared by mixing the mortar with water (each $1 \mathrm{~kg}$ of mortar with 0.23 liters of water) in an electric mixer. The geopolymeric-based mortar was produced in the laboratory based on activation of alkaline materials rich in silica and alumina. The mortar was obtained by a mixture of sand (1000 gr.), fly ash (280 gr.), sodium hydroxide (144 gr.), sodium silicate (144 gr.), selected based on previous experience of the authors.

The combination of the steel reinforcement with the selected mortars led to three systems:

- Lime-based pozzolanic mortar A reinforced with steel fiber mesh (SRGA)

- Lime-based pozzolanic mortar B reinforced with steel fiber mesh (SRGB)

- Geopolymeric-based mortar reinforced with steel fiber mesh (SRGG)

\subsection{Mechanical properties}

The mechanical properties of brick and mortar were obtained by performing compressive and flexural tests according to relevant test standards and procedures $[15,16]$. The brick specimens 
were prepared, cleaned, washed, and dried in an oven before performing the tests. Mortar specimens were prepared by pouring the mortar in steel or plastic molds, demolding after seven days, and then keeping in laboratory conditions until testing. The tests on mortar specimens were performed at different ages (30,60 and 90 days) to monitor the changes in mechanical properties along time.

The compressive tests were performed on $40 \mathrm{~mm}$ cubic brick specimens (in the flatwise direction), and on cylindrical mortar specimens with $50 \mathrm{~mm}$ diameter and $100 \mathrm{~mm}$ height, see Fig. 1(a, b). Flexural three-point bending tests were also performed on mortar prismatic specimens with dimensions of $40 \times 40 \times 160 \mathrm{~mm}^{3}$, see Fig. 1(c). The remaining half of the prismatic specimens, after performing the flexural tests, were used to perform another set of compressive tests. Six specimens were prepared and tested for each material type and test condition. The average mechanical properties and the corresponding coefficients of variations (CVs) are presented in Table 1.

It can be observed that the mechanical properties of all three mortar types are still increasing even after 90 days of curing showing that the pozzolanic/alkaline reactions have probably not finished yet. This observation has also been reported elsewhere in case of lime-based mortars [17,18]. Drying of the specimens with time may have led to reduction of required water for completion of pozzolanic reactions [19]. On the other hand, carbonation in lime mortars is a slow process and continues until several years until completion [20] which can be another the reason for the observed fluctuations in the mechanical properties. In general, Mortar A has a smaller elastic modulus, a comparable cylindrical compressive strength and a higher flexural tensile strength in comparison with Mortar B. Mortar G has the lowest mechanical properties among all three selected mortar types. 
Direct tensile tests were performed on steel fabrics with dimensions of $50 \times 450 \mathrm{~mm}$ (containing eight longitudinal cords) to obtain their tensile strength and elastic modulus. Aluminum tabs were glued to the ends of the specimens to ensure uniform stress distribution and prevent sliding in the gripping areas. The tests were performed with a universal testing machine, with a maximum load capacity of $200 \mathrm{kN}$ and under displacement control conditions with a constant velocity of $2 \mathrm{~mm} / \mathrm{min}$, see Fig. 1(d). The applied load was measured with the load cell integrated in the testing machine and the deformation was recorded by the internal LVDT and a $100 \mathrm{~mm}$ clip gauge mounted on the center of the specimens. The average tensile strength and Young's modulus of the steel mesh were obtained as $3070 \mathrm{MPa}$ and $190 \mathrm{GPa}$, respectively.

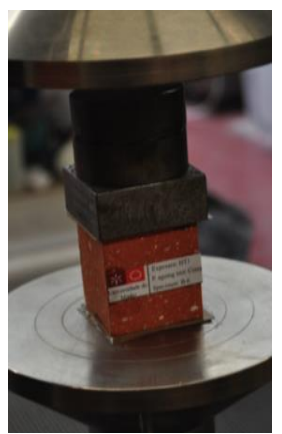

(a)

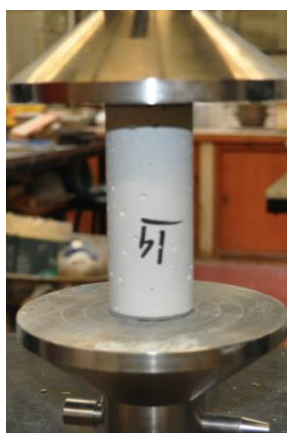

(b)

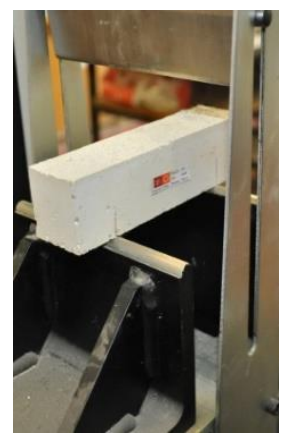

(c)

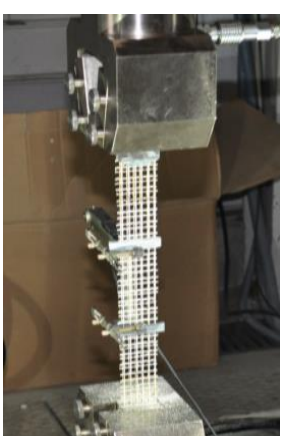

(d)

Fig. 1. Experimental setups for materials' mechanical characterization: (a) compressive test on brick; (b) compressive test on mortar; (c) flexural test on mortar; (d) direct tensile test on steel fabric.

Table 1. Mechanical properties of brick and mortars (CV in round brackets).

\begin{tabular}{|c|c|c|c|c|c|}
\hline Material & $\begin{array}{c}\text { Age } \\
\text { [days] }\end{array}$ & $\begin{array}{l}\mathrm{f}_{\mathrm{cm}-{ }_{\text {cubic }}{ }^{*}} \\
{\left[\mathrm{~N} / \mathrm{mm}^{2}\right]}\end{array}$ & $\begin{array}{l}\mathrm{f}_{\mathrm{cm}-\mathrm{cylinder}} \\
{\left[\mathrm{N} / \mathrm{mm}^{2}\right]}\end{array}$ & $\begin{array}{c}\mathrm{E}_{\mathrm{cm}} \\
{\left[\mathrm{kN} / \mathrm{mm}^{2}\right]}\end{array}$ & $\begin{array}{c}\mathrm{f}_{\mathrm{tm}} \\
{\left[\mathrm{N} / \mathrm{mm}^{2}\right]}\end{array}$ \\
\hline Brick & - & $14.0(4.0 \%)$ & - & $\begin{array}{l}\mathrm{E}_{\mathrm{x}}=8.51(7.9 \%) \\
\mathrm{E}_{\mathrm{y}}=4.14(14.8 \%)\end{array}$ & $6.42(11.2 \%)$ \\
\hline Lime based pozzolanic $\mathrm{A}$ & $\begin{array}{l}30 \\
60 \\
90\end{array}$ & $\begin{array}{l}9.78(9.7 \%) \\
10.73(6.7 \%) \\
13.21(10.1 \%)\end{array}$ & $\begin{array}{l}9.85(13.4 \%) \\
10.79(9.9 \%) \\
12.74(11.8 \%)\end{array}$ & $3.25(14.6 \%)$ & $\begin{array}{l}5.00(13.7 \%) \\
6.71(20.8 \%) \\
6.07(15.2 \%)\end{array}$ \\
\hline Lime based pozzolanic B & $\begin{array}{l}30 \\
60 \\
90\end{array}$ & $\begin{array}{l}11.60(13.4 \%) \\
14.19(14.3 \%) \\
18.12(12.8 \%)\end{array}$ & $\begin{array}{l}12.66(12.2 \%) \\
- \\
12.42(15.4 \%)\end{array}$ & $14.05(28.0 \%)$ & $\begin{array}{l}3.32(5.4 \%) \\
3.68(10.3 \%) \\
3.43(11.2 \%)\end{array}$ \\
\hline Geopolymer mortar G & $\begin{array}{l}30 \\
60 \\
90\end{array}$ & $\begin{array}{l}4.16(13.8 \%) \\
3.63(12.2 \%) \\
4.19(13.8 \%)\end{array}$ & $\begin{array}{l}5.22(15.7 \%) \\
3.50(21.4 \%) \\
6.48(4.0 \%)\end{array}$ & $13.7(9.35 \%)$ & $\begin{array}{l}1.68(2.6 \%) \\
1.68(20.0 \%) \\
1.23(16.8 \%)\end{array}$ \\
\hline
\end{tabular}

$*_{f_{\text {cm-cubic }}}$ is the cubic compressive strength; $\mathrm{f}_{\mathrm{cm}-\mathrm{cylinder}}$ is the cylindrical compressive strength; $\mathrm{E}_{\mathrm{cm}}$ is the compressive elastic modulus; and $\mathrm{f}_{\mathrm{tm}}$ is the flexural tensile strength. 


\subsection{Single fiber-to-mortar bond behavior}

Several test setups have been used in the literature for investigating the bond behavior between fibers and brittle matrices (such as epoxy resin or concrete), see e.g. [21-26]. One-sided or doublesided pull-out tests are among the most conventional methods. The one-sided pull-out test, being more popular due to the simplicity of the test setup and specimen configuration, is used in this study.

The specimens consisted of single steel cords embedded in mortar cylinders with $75 \mathrm{~mm}$ diameter and different heights (representing different bonded lengths) of 100, 150, 200 and $250 \mathrm{~mm}$, see Fig. 2. The steel cords were initially placed inside PVC molds and were restrained at both ends, at the central section of the molds, to assure a straight alignment inside the specimens. The mortar was then poured in two layers inside the molds with special care. After addition of each layer, a vibrating table was used for suitably compacting the mortar to avoid any voids in the specimens especially near the fiber-to-mortar interface region. The specimens were prepared in laboratory conditions $\left(20^{\circ} \mathrm{C}\right.$ and $60 \%$ R.H.), demolded after seven days, and were stored in the same conditions for three months (counted from the preparation day) before testing. Five specimens were prepared for each mortar type and bonded length resulting in total 60 specimens.

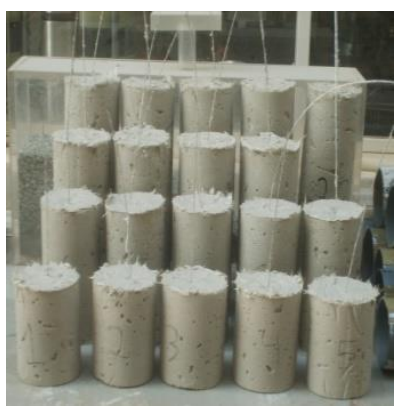

(a)

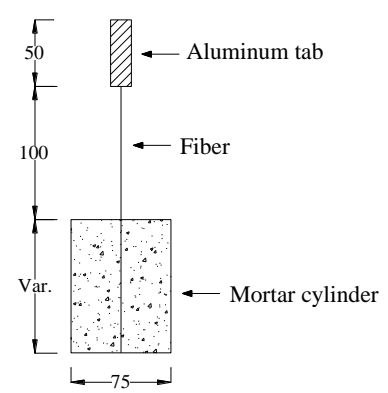

(b)

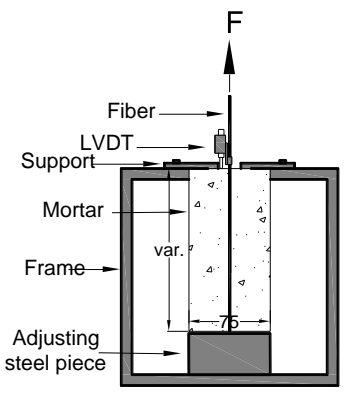

(c)

Fig. 2. (a) Specimens prepared for pull-out tests; (b) geometrical details of the specimens; (c) test setup. 
The tests were performed following the one-sided pull-out scheme by blocking the specimens to a rigid frame and pulling the fibers from their free end. A servo-hydraulic system with a maximum capacity of $20 \mathrm{kN}$ was used for performing the tests, see Fig. 2(c). Aluminum tabs were glued at the fibers' free end to facilitate gripping, see Fig. 2(b). The specimens were fairly clamped to the supporting frame to avoid any movements during the tests. The tests were driven under displacement control conditions with reference to the internal LVDT of the system by pulling the fibers with a velocity of $0.3 \mathrm{~mm} / \mathrm{min}$. The resultant load, measured by the load cell integrated in the testing machine, was divided by the cross section area of the dry fibers to calculate the applied stress. Displacements were recorded by the transducer of the testing machine. The slip of the fibers from the mortar was measured by an LVDT mounted on the fibers.

Measurement of the slip in this test setup was found challenging due to the flexibility of the fibers and geometrical details of the test setup. Banholzer [27] embedded the fibers in a resin block to facilitate the gripping and slip measurements in one-sided pull-out tests. In the current study, the fibers were bare and the gripping was applied directly on the aluminum plates attached to the fibers. A small preload was thus applied to the fibers to reduce their flexibility and to facilitate attachment of the LVDT to the fibers. As it was not possible to attach the LVDT base in the vicinity of the mortar-to-fiber interface, it was mounted at a distance of $l=20 \mathrm{~mm}$ from the mortar surface. The slip was then calculated as the recorded displacements minus the elastic elongation of the unbonded textile $\varepsilon \boldsymbol{\ell}, \varepsilon$ being evaluated as the applied load divided by the section area and the Young's modulus $E_{\mathrm{s}}$ of the fiber.

\subsection{SRG tensile behavior}

Direct tensile tests were performed on SRG coupons to investigate their nonlinear tensile response and tension stiffening behavior. The geometrical details of the specimens are presented in Fig. 
3(a). Prismatic specimens were manufactured, using wooden molds, with $10 \mathrm{~mm}$ thickness, $200 \mathrm{~mm}$ length and $50 \mathrm{~mm}$ width. $150 \mathrm{~mm}$ length of the fibers were left out of the mortar at both ends to provide space for gripping. The textiles were placed in the middle and were pressed slightly inside the mortar with special care to ensure their linearity. Each coupon was made individually, that is, they were not cut from a larger plate. The specimens were demolded after seven days and were stored in laboratory conditions for 90 days before testing. Five specimens were prepared and tested for each SRG system leading to a total of 15 specimens.

The tests were performed using a universal testing machine with maximum load capacity of $200 \mathrm{kN}$ under displacement control conditions. The experimental test setup is shown in Fig. 3(b). Aluminum tabs were used for application to the dry textile out of the matrix to provide an appropriate gripping area. The specimens were pulled monotonically with a constant velocity of $0.3 \mathrm{~mm} / \mathrm{min}$. The load, measured by the load cell integrated in the testing machine, was divided by the cross section area of the dry textile to calculate the applied stress. Displacements were recorded by the transducer of the testing machine, that provided a global measure from end plate to end plate, and by LVDTs placed on the mortar matrix, with a $100 \mathrm{~mm}$ measurement base. Average strains were calculated in two different ways: (a) (The displacements recorded by transducer of the testing machine minus the elastic deformation of dry textile out of the mortar) divided by the mortar length. The elastic deformation of the dry textile was evaluated as (Young's modulus, $\left.E_{\mathrm{s}}\right) \times($ textile cross section area, $A) /($ free textile length out of the mortar, L); (b) the recorded displacements by the LVDT placed on the mortar divided by the base length of the LVDT. The use of full-field measurement techniques (such as digital image correlation) is also interesting to record the displacement fields and crack development on the mortar surface which 
can be transformed to mortar average tensile response [28]. The latter is out of the scope of this study and is not considered in this experimental campaign.

Several gripping methods have been used in the literature for tensile characterization of textile reinforced mortars and concrete. In most cases, the grip is directly applied on the mortar surface. According to Hartig et al. [29], these systems can been classified to stiff and flexible according to the governing load transfer mechanisms. In the stiff method, a steel plate is glued on the mortar to prepare the gripping area. The main load transfer mechanism between the specimen and the grip in this system is shear and tension and no fiber slipping from the mortar occurs at the gripping area. In the flexible system, however, the load transfer between the specimen and the grip is based on friction, and slipping can occur in case if the friction is not sufficient. However, it should be noted that, according to the experimental results reported in the literature, avoiding slippage of the fibers is a complex task even in the stiff gripping systems. Application of high pressures to the specimens, necessary to avoid slipping, can lead to cracking, torsion or crushing of the specimens especially when the mortar thickness is small. On the other hand, there is also no practical way of controlling if the slip has really occurred or not in these systems. The slip, even in small amounts, can lead to incorrect calculation of stresses transferred to the steel fibers and thus miscalculations in the TRM tensile strength.

The advantage of direct application of the grips on the dry textile, as is done in this study, is that slipping is completely avoided in the gripping area. Moreover, the applied stresses on the steel fibers can be correctly calculated as the loads are directly transferred from the grip to the fibers and then to the mortar and not from the mortar to the fibers. On the other hand, the load application in this gripping system is similar to the fiber pull-out and single-lap shear bond tests and the results are thus compatible. Moreover, the results provide a clear insight into the tension stiffening behavior of the 
mortar and average response of fibers in TRM systems and thus can be used for development of constitutive laws.

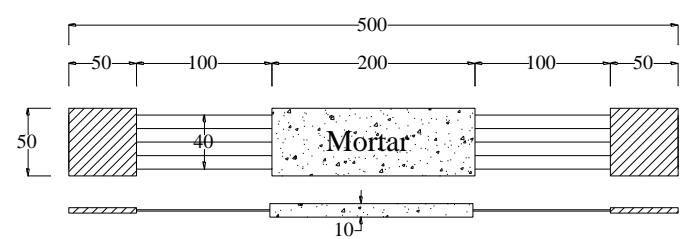

(a)

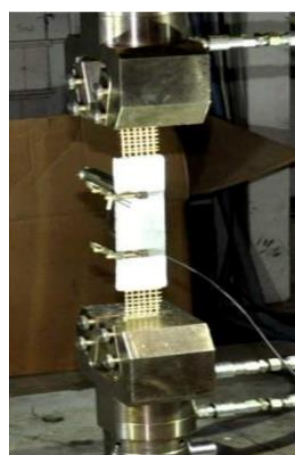

(b)

Fig. 3. (a) Geometrical details of fiber reinforced mortar specimens; (b) experimental setup for tensile characterization of SRG composites.

\subsection{SRG-to-brick bond behavior}

Single-lap shear bond tests were performed on SRG-strengthened bricks with the geometrical details presented in Fig. 4(a, b). The bonded length $\left(\mathrm{L}_{b}\right)$ was $150 \mathrm{~mm}$ (leaving a $40 \mathrm{~mm}$ unbonded length near the loaded end) and the width of the bonded area was $50 \mathrm{~mm}$. Five specimens were prepared for each combination of mortar and fiber type resulting in total 15 specimens.

The reinforcement was applied to one side of the brickwork following a standard wet lay-up procedure, according to the recommendations provided by the suppliers. The substrate was cleaned and dust was removed with an air compressor. The bricks were then immersed in water for 24 hours to avoid absorption of water from the fresh mortar. A $5 \mathrm{~mm}$ thick layer of the mortar matrix was then applied on the bond area by means of aluminum frameworks. The textile was then placed by hand and pressed slightly into the fresh mortar, to allow its protrusion through the voids between cords/ropes. Finally, another $5 \mathrm{~mm}$ thick layer of the mortar was applied on top, leading to a total mortar thickness of $10 \mathrm{~mm}$. The specimens were kept in the laboratory conditions for three months before testing. 


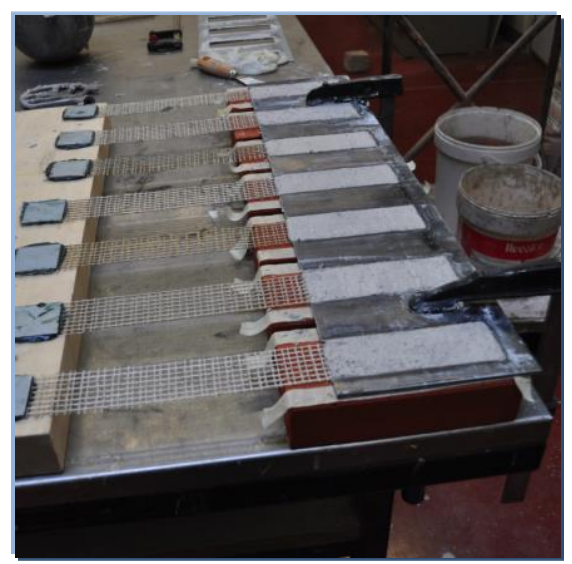

(a)

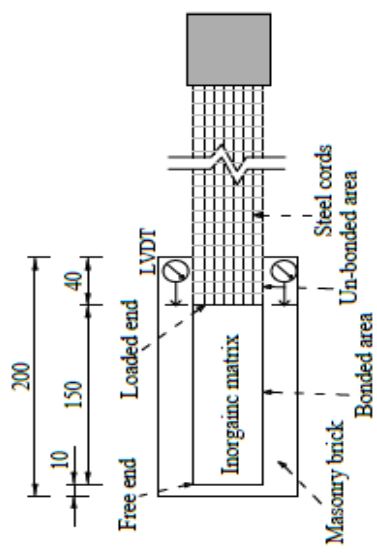

(b)

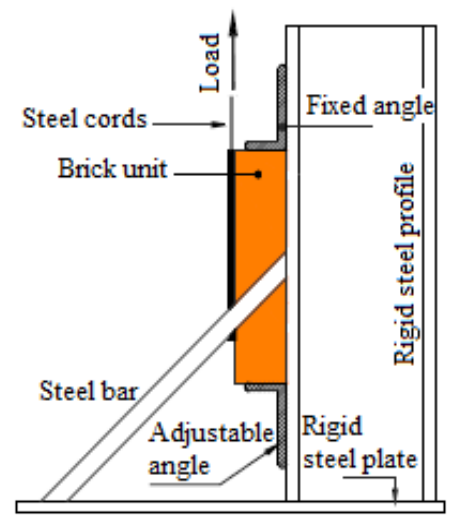

Fig. 4. (a) Specimens prepared for single-lap pull out tests; (b) geometrical details of the specimens; (c) single-lap shear bond test setup.

The tests were carried out with a single-lap scheme, by blocking the specimens and pulling the unbonded textile from above using a universal testing machine, see Fig. 4(c). A stiff supporting steel frame, that ensured the alignment between the tensile load applied to the unbonded textile and the middle plane of the reinforcement, was used to support the specimens. It was therefore ensured that the reinforcement-to-substrate interface was subjected to a pure shear stress at fibersto-mortar interface. For avoiding rotations of the specimens during test execution, the specimens were gripped at lateral sides. The unbonded textile was left dry, but its' end was reinforced with aluminum plates for clamping to ensure that a uniform load was transferred to all the cords/ropes and avoid their premature rupture in the gripping area.

The tests were driven under displacement control conditions with reference to the internal LVDT of the system. The strips were pulled monotonically with a velocity of $0.3 \mathrm{~mm} / \mathrm{min}$ and the resulting load was measured by means of the internal load cell. The textile global slip was measured by means of two LVDTs mounted at the loaded end. One end of the LVDT was fixed to the substrate and the other one to the unbonded textile (making use of metal plates), at the vicinity of the bonded area. Measurement of the slip with LVDTs in these tests is rather challenging due 
to the flexibility of the fiber fabric which can lead to inaccurate readings by LVDTs. A solution to this problem can be application of a preload to the specimens before starting the tests. Application of the so-called feature tracking method [28] seems also interesting for accurate measurement of the slip from the matrix. The latter is out of the scope of this study and is not considered here.

\section{Single fiber pull-out tests results}

The results were obtained in terms of force-slip curves and failure mode of the specimens. The envelope and average of force-slip curves are presented for all bonded lengths and mortar types in Fig. 5 to Fig. 7. The details of the experimental results obtained for each specimen are also presented in Table 2. The results, besides in some cases, have a low variation and thus the envelopes are tight. The tests were continued until the last stage of the softening range in the forceslip curves (with around 40 to $50 \mathrm{~mm}$ fiber slip) with the exception of SRGA specimens with $l_{\mathrm{b}}=200 \mathrm{~mm}$ in which the tests were stopped at $15 \mathrm{~mm}$ slip (due to practical problems with the hydraulic jack encountered during the tests).

The failure mode of the specimens was slipping of the fiber from the mortar in all bonded lengths and mortar types, with the exeption of SRGB specimens with $l_{b}=200 \mathrm{~mm}$ in which the tensile failure of the fibers occurred. As the tensile strength of the fibers was less than the bond strength in these latter specimens, the SRGB specimens with $l_{\mathrm{b}}=250 \mathrm{~mm}$ were not tested anymore as a similar behavior (failure mode and peak load) was expected.

In all cases with fiber slipping failure mode, the observed force-slip behavior follows the typical response of fiber pull-out tests. The curves consist of three main stages [22,30-33]: (1) linear stage: in which the stresses are transferred from the fiber to the matrix without occurrence of any interfacial cracking. The recorded slip is the result of elastic deformation of the fiber and the elastic 
shear deformation of the fiber-mortar interface; (2) nonlinear stage: initiation of this stage is corresponding to first breakage of chemical bonds between the fiber and the matrix and thus initiation of debonding. During this stage, the debonding progresses by increasing the slip, as chemical bonds break, until complete debonding of the fiber along the bond length; (3) softening stage: in which only frictional bond between the fiber and the matrix exists. The force gradually decreases in this stage with increment of slip due to the slippage of the fiber from the matrix. The force-slip curve of SRGB specimens with $l_{\mathrm{b}}=200 \mathrm{~mm}$, with fiber tensile rupture failure, consists of the first stage and a small portion of the second stage, as expected.

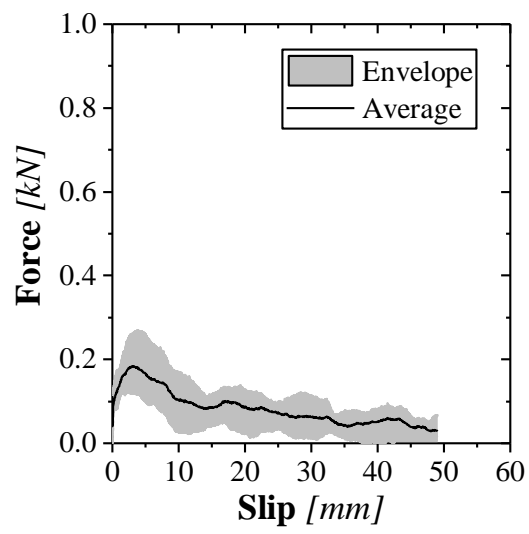

(a)

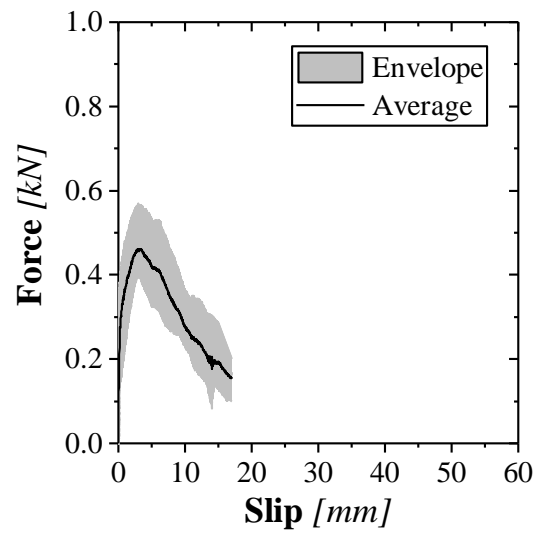

(c)

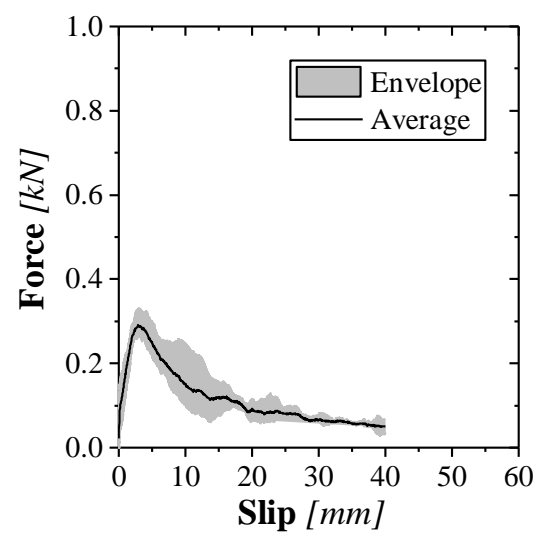

(b)

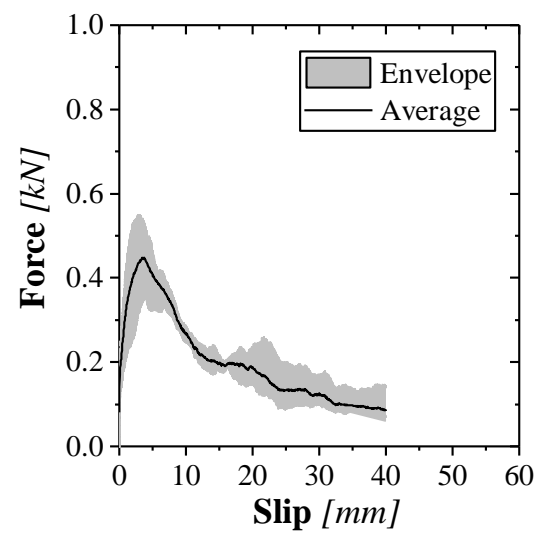

(d)

Fig. 5. Experimental force-slip curves for SRGA system: (a) $l_{\mathrm{b}}=100 \mathrm{~mm}$; (b) $l_{\mathrm{b}}=150 \mathrm{~mm}$; (c) $l_{\mathrm{b}}=200 \mathrm{~mm}$; (d) $l_{\mathrm{b}}=250 \mathrm{~mm}$. 


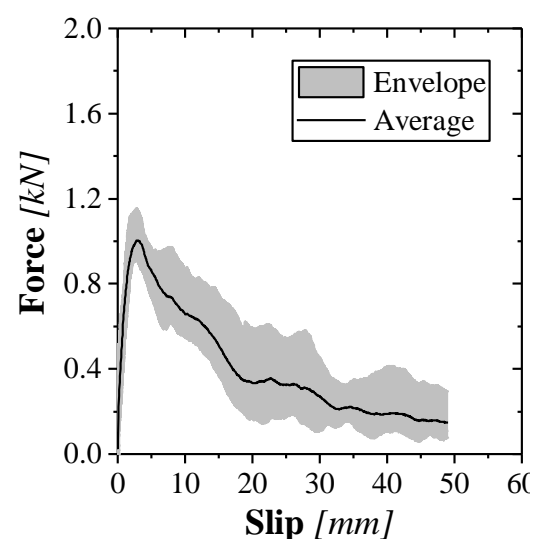

(a)

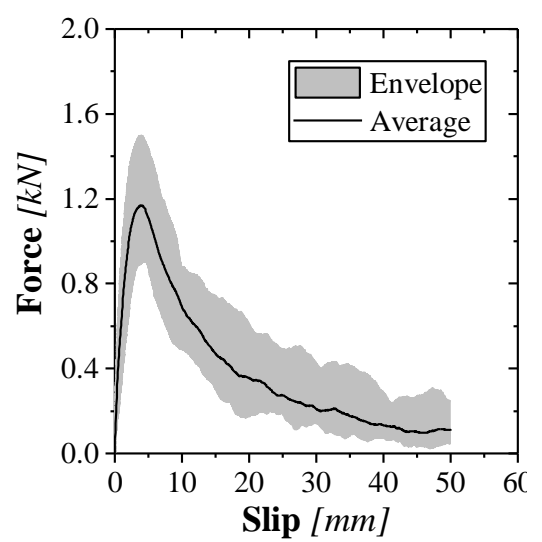

(b)

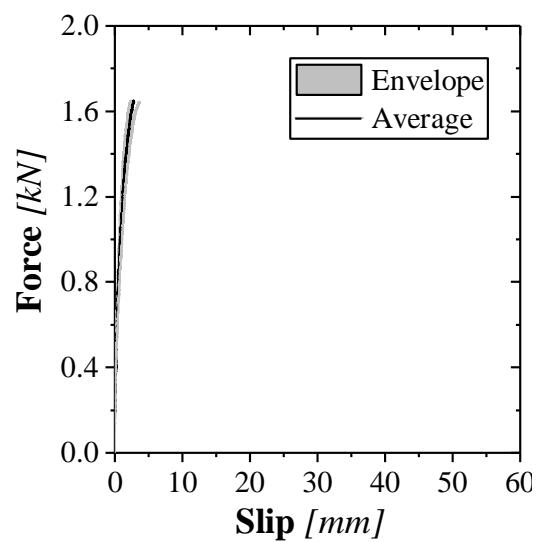

(c)

Fig. 6. Experimental force-slip curves for SRGB system: (a) $l_{\mathrm{b}}=100 \mathrm{~mm}$; (b) $l_{\mathrm{b}}=150 \mathrm{~mm}$; (c) $l_{\mathrm{b}}=200 \mathrm{~mm}$.

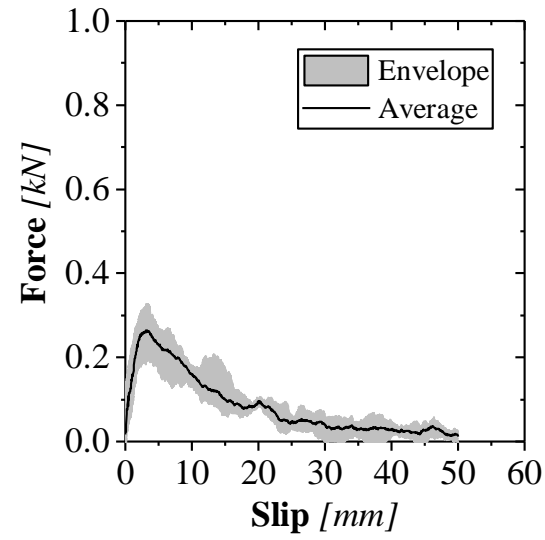

(a)

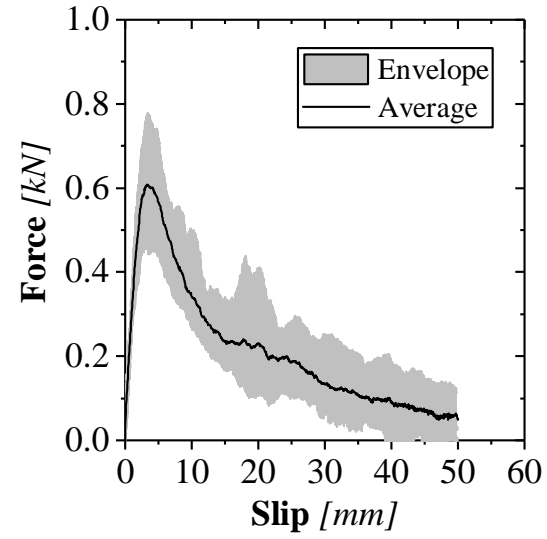

(c)

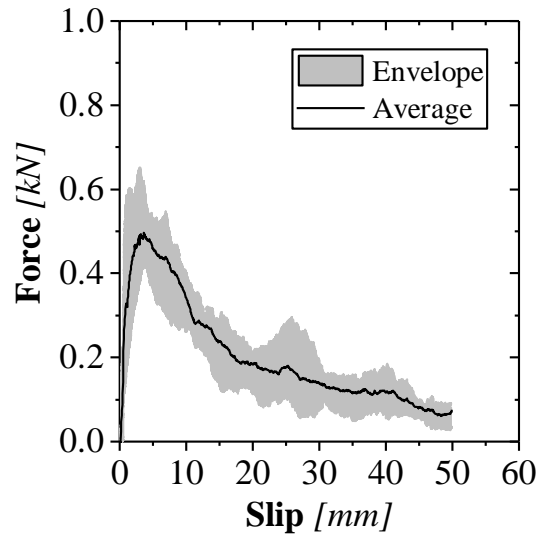

(b)

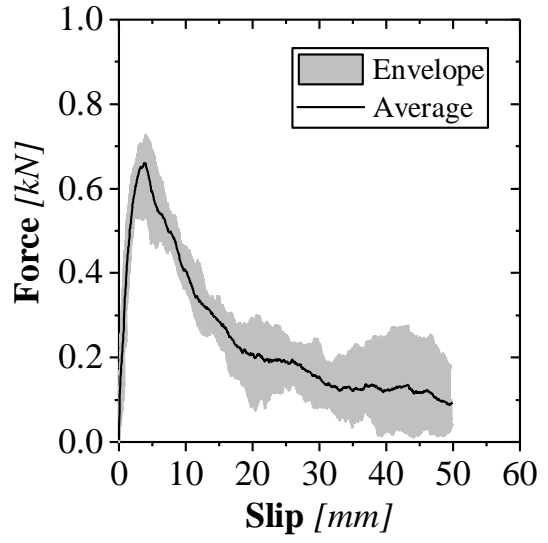

(d)

Fig. 7. Experimental force-slip curves for SRGG system: (a) $l_{\mathrm{b}}=100 \mathrm{~mm}$; (b) $l_{\mathrm{b}}=150 \mathrm{~mm}$; (c) $l_{\mathrm{b}}=200 \mathrm{~mm}$; (d) $l_{\mathrm{b}}=250 \mathrm{~mm}$. 
Table 2. Results of single fiber pull-out tests on SRG systems*.

\begin{tabular}{|c|c|c|c|c|c|c|c|c|}
\hline Specimen & $\begin{array}{l}\text { Bonded length } \\
{[\mathrm{mm}]}\end{array}$ & $\begin{array}{l}F_{\max } \\
{[\mathrm{kN}]}\end{array}$ & $\begin{array}{c}\sigma_{\max } \\
{[\mathrm{MPa}]}\end{array}$ & $\mathrm{CV}(\%)$ & $\begin{array}{c}\mathrm{S}_{\mathrm{p}} \\
{[\mathrm{mm}]}\end{array}$ & $\mathrm{CV}(\%)$ & $\eta_{\mathrm{s}}=\mathrm{f}_{\mathrm{b}} / \mathrm{f}_{\mathrm{s}}$ & $\mathrm{FM}^{* *}$ \\
\hline SRGA & 100 & 0.18 & 334.57 & 17.7 & 2.95 & 25.0 & $10.90 \%$ & $S$ \\
\hline SRGA & 150 & 0.29 & 539.03 & 10.2 & 3.00 & 7.6 & $17.56 \%$ & S \\
\hline SRGA & 200 & 0.46 & 855.02 & 22.2 & 2.95 & 16.5 & $27.85 \%$ & $S$ \\
\hline SRGA & 250 & 0.46 & 855.02 & 23.6 & 3.42 & 11.1 & $27.85 \%$ & $S$ \\
\hline SRGB & 100 & 0.96 & 1784.39 & 17.5 & 2.98 & 6.8 & $58.12 \%$ & $S$ \\
\hline SRGB & 150 & 1.17 & 2174.72 & 20.0 & 3.90 & 10.3 & $70.84 \%$ & S \\
\hline SRGB & 200 & 1.57 & 2918.22 & 8.8 & 2.91 & 22.0 & $95.06 \%$ & $\mathrm{R}$ \\
\hline SRGG & 100 & 0.26 & 483.27 & 16.2 & 3.07 & 16.3 & $15.74 \%$ & $S$ \\
\hline SRGG & 150 & 0.50 & 929.37 & 14.1 & 3.97 & 19.5 & $30.27 \%$ & S \\
\hline SRGG & 200 & 0.61 & 1133.83 & 18.7 & 3.28 & 20.2 & $36.93 \%$ & S \\
\hline SRGG & 250 & 0.66 & 1226.77 & 11.4 & 3.53 & 11.9 & $39.96 \%$ & $S$ \\
\hline
\end{tabular}

The average force-slip curves for different bond lengths are compared in Fig. 8. It can be observed that the maximum pull-out force $\left(F_{\max }\right)$ and the slope of the initial elastic region increase with bond length in all mortar types (until $200 \mathrm{~mm}$ bond length). On the other hand, no specific change in the peak slip $\left(\mathrm{S}_{\mathrm{p}}\right)$ is observable, see Table 2 .

The $F_{\max }$ in SRGA and SRGG specimens increases only until bond length of $200 \mathrm{~mm}$. This indicates that the effective bond length, $l_{\mathrm{e}}$, is in the range of $200 \mathrm{~mm}<l_{\mathrm{e}}<250 \mathrm{~mm}$ in these systems. Razavizadeh et al. [14] also obtained a similar numerical value for the effective bond length in a similar SRG system. On the other hand, the $F_{\max }$ in SRGB specimens increases until fiber tensile rupture at $200 \mathrm{~mm}$ bond length. The tensile rupture of the steel fiber in SRGB shows the effective bond length is in the range of $150 \mathrm{~mm}<l_{e},<200 \mathrm{~mm}$. The $F_{\max }$ in SRGB specimens is always higher than SRGA which can be attributed to the higher elastic modulus of mortar B and the different bond mechanisms existing in these two systems. On the other hand, the bond strength in SRGG system is comparable to SRGA system, although mortar $\mathrm{G}$ has a lower mechanical properties than mortar A. 
Table 2 shows the bond efficiency, defined as the ratio of $F_{\max }$ to the tensile strength of the fiber, is highest in SRGB system in comparison to the other SRG systems. A detailed microstructural analysis of bond in the systems under study is interesting in better understanding the mechanisms affecting the bond efficiency and is proposed for future investigations.

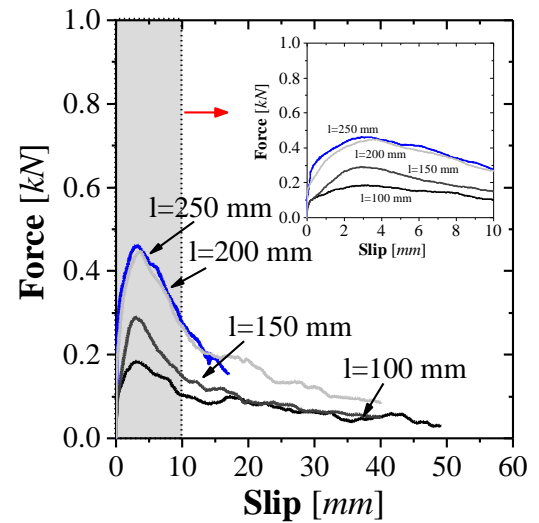

(a)

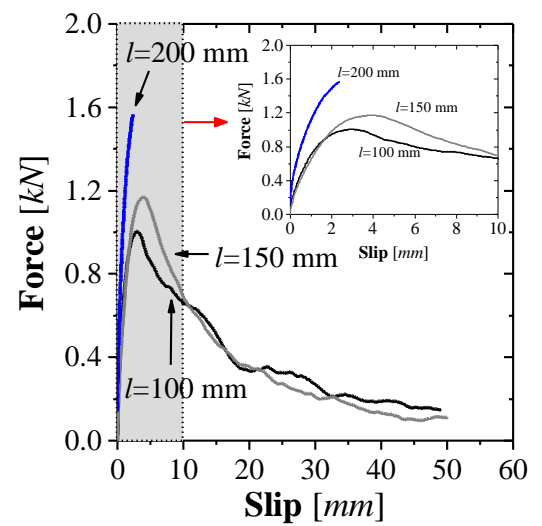

(b)

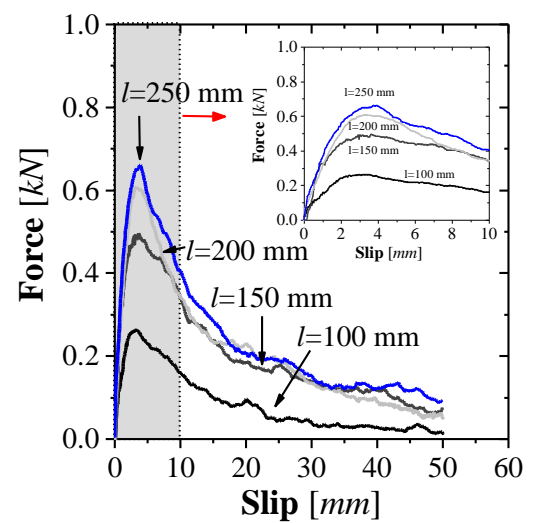

(c)

Fig. 8. Average force-slip curves for: (a) SRGA; (b) SRGB; (c) SRGG.

\section{Tensile tests results}

The average tensile stress-strain curves and the envelope of the experimental results are presented in Fig. 9. The scatter of the experimental results is again relatively low. The average is made of five valid test results for SRGA and SRGG systems and four valid test results for SRGB system. One of the SRGB specimens cracked during preparation of the test setup and therefore is not considered here. As explained before, the curves represent the fibers stress versus the average strain of the fibers embedded in the mortar. The presented stress-strain curves can thus be considered as the average response of embedded fibers and can thus be used as input for numerical modeling purposes [34].

The tensile response of textile reinforced mortars usually consists of three stages $[10,29,35-37]$ :

(I) un-cracked stage, in which the mortar matrix contributes to both load bearing capacity and stiffness. In this stage, the matrix is still elastic and the behavior is mainly governed by the matrix 
properties; (II) crack development, during which the cracks develop progressively. The wellknown tension stiffening effect due to the bond between reinforcement and matrix is active in this stage; and (III) cracked, in which the crack pattern is completely developed. Due to the loss of interaction between the reinforcement and the matrix in this stage, the tensile curve settles on the elastic modulus of the dry fibers. However, the stiffness of the curve in this stage is usually less than that of the dry fibers. The imperfect bond between the yarn the and the matrix [38], or nonuniform distribution of stresses between the cords can be the reasons for this phenomenon. Soranakom and Mobasher [38] proposed axial stiffness efficiency factors in the range of 0.35 1.0 to account for this effect. It should be noted that the existence of all these stages in the tensile response depends on several factors including (i) the system properties such as tensile strength and the Young's modulus of the matrix, the layout of the fabric, the cord/fiber-to-mortar bond properties $[1,10,29,37]$ and (ii) the test setup.

As for the SRG systems used in this study, the first and third stages are clearly identifiable in all the experimental results. A smooth transition from Stage I to III can also be observed in SRGA and SRGG systems (representing stage II). However, this transition is not clear in SRGB system. This observation, also reported in De Santis and de Felice [10] for SRG coupons made of a limebased mortar, can be due to several reasons including existence of a weak cord-to-matrix interlocking mechanism, low mortar mechanical properties, early cracking of the mortar, etc.

The weak cord-to-matrix interlocking is probably not the case as the single fiber pull-out tests showed the SRGB system has the highest bond strength, see Fig. 8. However, this comparison between the pull-out test and tensile test results should be made with special care. The bond mechanisms are probably different in these two specimen types due to the differences in the matrix size and the reinforcement configuration. The tensile test specimens have smaller mortar thickness 
and are reinforced with fabric (rather than a single fiber) containing eight steel fibers connected with a plastic mesh in the transverse direction. This plastic mesh, which is provided for conservation of the mesh structure, can affect the bond behavior. The differences between the single fiber-to-mortar and fabric-to-mortar bond behavior needs to be clarified and better investigated in the future studies.

No clear conclusion can also be made about the effect of mortar mechanical properties on the observed tensile response. Mortar $\mathrm{G}$ has the lowest flexural tensile strength, see Table 1, but the tensile response of SRGG system is composed of a clear three stage behavior. It therefore seems that other factors may have resulted in this observation in the SRGB system. Early cracking of the mortar (due to workmanship problems or drying shrinkage), mortar thickness variations, or the non-uniform application of stresses between the fibers are among the factors that can lead to such a behavior.

The detailed results of direct tensile tests are presented in Table 3 in terms of the stress and the strain of the transition points between stages I and II $\left(\sigma_{\mathrm{I}}, \varepsilon_{\mathrm{I}}\right)$ and between stages II and III $\left(\sigma_{\mathrm{II}}, \varepsilon_{\mathrm{II}}\right)$, the peak stress $\left(\sigma_{t}\right)$ and strain $\left(\varepsilon_{t}\right)$, and the Young's modules in each stage $\left(\mathrm{E}_{\mathrm{I}}, \mathrm{E}_{\mathrm{II}}, \mathrm{E}_{\mathrm{III}}\right)$. The values are obtained based on the experimental results and are subjected to measurement errors due to the fact that they are usually representative of a region rather than a specific point (such as $\sigma_{\mathrm{I}}, \sigma_{\mathrm{II}}$ ). $\mathrm{E}_{\mathrm{I}}$ is obtained as $\sigma_{\mathrm{I}} / \varepsilon_{\mathrm{I}}, \mathrm{E}_{\mathrm{II}}$ as $\left(\sigma_{\mathrm{II}-} \sigma_{\mathrm{I}}\right) /\left(\varepsilon_{\mathrm{II}}-\varepsilon_{\mathrm{I}}\right)$, and $\mathrm{E}_{\mathrm{III}}$ as the linear slope of the curve in the third stage. The values related to stages I and II are not calculated and presented for SRGB system as the transition stage was not clear in these specimens. The obtained values for SRGA and SRGG systems are very similar in all three stages. The tensile strength is however slightly different which can be due to the lower mortar-to-cord bond strength and non-uniform distribution of stresses on the fibers in SRGA system (which led to individual failure of some fibers during the tests). The 
average tensile strength is $2627 \mathrm{MPa}, 3137 \mathrm{MPa}$, and $2948 \mathrm{MPa}$ for SRGA, SRGB, and SRGG systems representing efficiency factors of $0.86,1.00$ and 0.96 , respectively. The elastic modulus of all three systems in the third stage, $\mathrm{E}_{\text {III }}$, is also similar and lower than the bare fibers. This value is $124 \mathrm{GPa}$ for SRGA and SRGG and $139 \mathrm{GPa}$ for SRGB systems representing a 0.65 and 0.73 efficiency factors, respectively. Although all three SRG systems show an acceptable tensile response, it seems that SRGB and SRGG systems have the best performance in terms of utilization of the reinforcement tensile strength.

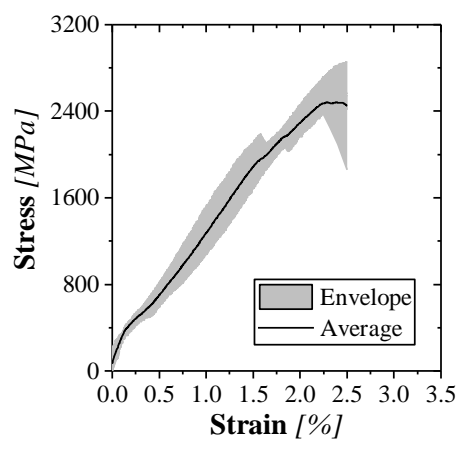

(a)

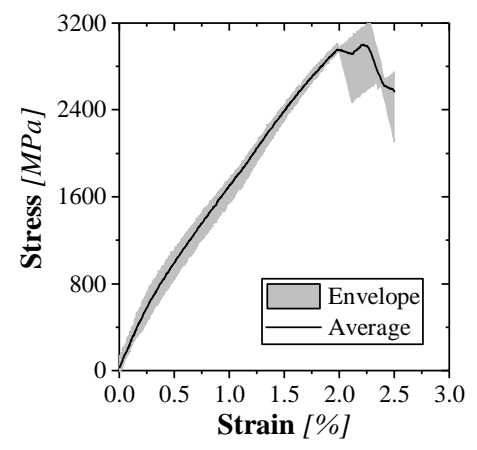

(b)

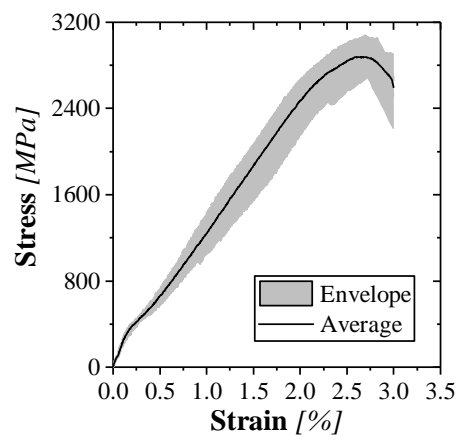

(c)

Fig. 9. Experimental tensile response of tested SRG systems: (a) SRGA; (b) SRGB; (c) SRGG.

Table 3. Results of direct tensile tests on SRG systems*.

\begin{tabular}{|c|c|c|c|c|c|c|c|c|c|}
\hline \multirow[b]{2}{*}{ Specimen } & \multicolumn{3}{|c|}{ Stage I } & \multicolumn{3}{|c|}{ Stage II } & \multicolumn{3}{|c|}{ Stage III } \\
\hline & $\begin{array}{c}\sigma_{\mathrm{I}} \\
{\left[\mathrm{N} / \mathrm{mm}^{2}\right]}\end{array}$ & $\begin{array}{c}\varepsilon \mathrm{I} \\
{[\%]}\end{array}$ & $\begin{array}{c}\mathrm{E}_{\mathrm{I}} \\
{\left[\mathrm{kN} / \mathrm{mm}^{2}\right]}\end{array}$ & $\begin{array}{c}\sigma_{\mathrm{II}} \\
{\left[\mathrm{N} / \mathrm{mm}^{2}\right]}\end{array}$ & $\begin{array}{c}\varepsilon I I \\
{[\%]}\end{array}$ & $\begin{array}{c}\mathrm{E}_{\mathrm{II}} \\
{\left[\mathrm{kN} / \mathrm{mm}^{2}\right]}\end{array}$ & $\begin{array}{c}\sigma_{\mathrm{t}} \\
{\left[\mathrm{N} / \mathrm{mm}^{2}\right]}\end{array}$ & $\begin{array}{c}\varepsilon \mathrm{t} \\
{[\%]}\end{array}$ & $\begin{array}{c}\text { EIII } \\
{\left[\mathrm{kN} / \mathrm{mm}^{2}\right]}\end{array}$ \\
\hline SRGA-1 & 404 & 0.14 & 293 & 537 & 0.32 & 74 & 2428 & 2.22 & 132 \\
\hline SRGA-2 & 328 & 0.16 & 209 & 515 & 0.38 & 83 & 2752 & 2.87 & 119 \\
\hline SRGA-3 & 280 & 0.13 & 215 & 558 & 0.32 & 146 & 2890 & 2.59 & 119 \\
\hline SRGA-4 & 410 & 0.15 & 268 & 592 & 0.32 & 108 & 2514 & 2.46 & 138 \\
\hline SRGA-5 & 376 & 0.14 & 269 & 500 & 0.40 & 48 & 2557 & 2.51 & 111 \\
\hline Average & 360 & 0.14 & 251 & 540 & 0.35 & 92 & 2628 & 2.53 & 124 \\
\hline $\mathrm{CV}$ & $15.30 \%$ & $7.76 \%$ & $14.63 \%$ & $6.71 \%$ & $11.43 \%$ & $40.74 \%$ & $7.17 \%$ & $9.28 \%$ & $8.84 \%$ \\
\hline SRGB-1 & - & - & - & - & - & - & 3157 & 2.21 & 131 \\
\hline SRGB-2 & - & - & - & - & - & - & 3204 & 2.28 & 148 \\
\hline SRGB-3 & - & - & - & - & - & - & 3010 & 1.98 & 130 \\
\hline SRGB-4 & - & - & - & - & - & - & 3176 & 2.26 & 147 \\
\hline Average & - & - & - & - & - & - & 3137 & 2.18 & 139 \\
\hline $\mathrm{CV}$ & - & - & - & - & - & - & $2.76 \%$ & $6.33 \%$ & $7.07 \%$ \\
\hline SRGG-1 & 366 & 0.18 & 206 & 505 & 0.417 & 58 & 2763 & 2.95 & 102 \\
\hline
\end{tabular}




\begin{tabular}{cccccccccc} 
SRGG-2 & 321 & 0.17 & 191 & 496 & 0.320 & 115 & 2927 & 2.54 & 132 \\
SRGG-3 & 387 & 0.17 & 225 & 591 & 0.394 & 92 & 3077 & 2.69 & 131 \\
SRGG-4 & 369 & 0.18 & 201 & 618 & 0.494 & 80 & 3057 & 2.82 & 138 \\
SRGG-5 & 317 & 0.19 & 166 & 513 & 0.375 & 107 & 2916 & 2.93 & 118 \\
\hline Average & 352 & 0.18 & 198 & 545 & 0.400 & 90 & 2948 & 2.79 & 124 \\
CV & $8.87 \%$ & $5.16 \%$ & $10.93 \%$ & $10.25 \%$ & $15.90 \%$ & $24.83 \%$ & $4.30 \%$ & $6.18 \%$ & $11.59 \%$ \\
\hline
\end{tabular}

* Failure mode in all the specimens was tensile rupture of the fibers

\section{SRG-to-brick bond tests results}

The results of the shear bond tests are obtained as the peak reinforcement stress $\left(\mathrm{f}_{\mathrm{b}}\right)$, the corresponding load per unit width $\left(\mathrm{F}_{\mathrm{b}}\right)$, the slip at peak $\left(\mathrm{s}_{\mathrm{p}}\right)$, and the exploitation ratio of the reinforcement tensile strength $\left(\left(\eta_{s}=f_{b} / f_{s}\right)\right.$. The data are presented in Table 4 together with the observed failure modes according to the following classification, see Fig. 10: debonding with cohesive failure of the substrate (A), debonding at the matrix-to-substrate (B) or at the textile-tomatrix $(C)$ interface, textile slippage within the matrix without (D) or with (E) cracking of the outer layer of mortar (very similar to each other and sometimes barely distinguishable both being governed by sliding of the cords/ropes), and, finally, tensile rupture of the textile out of the bonded area $(F)$. It should be noted that the association of a unique failure mode to the specimens is a challenging task as a combination of different failure modes was observed in many test samples. The envelope and average of experimental force-slip curves are presented in Fig. 11.

Table 4. Results of single-lap shear bond tests on SRG systems.

\begin{tabular}{ccccccccc}
\hline Specimen & $\mathrm{F}[\mathrm{kN}]$ & $\begin{array}{c}\mathrm{f}_{\mathrm{b}} \\
{\left[\mathrm{N} / \mathrm{mm}^{2}\right]}\end{array}$ & $\mathrm{F}_{\mathrm{b}}[\mathrm{kN} / \mathrm{m}]$ & $\mathrm{CV}(\%)$ & $\mathrm{s}_{\mathrm{p}}[\mathrm{mm}]$ & $\mathrm{CV}(\%)$ & $\eta_{\mathrm{s}}=\mathrm{f}_{\mathrm{b}} / \mathrm{f}_{\mathrm{s}}$ & $\mathrm{FM}$ \\
\hline $\mathrm{GA}$ & 5.29 & 1229.09 & 105.80 & 16.8 & 1.51 & 37.1 & $40.0 \%$ & $\mathrm{~d}$ \\
$\mathrm{~GB}$ & 4.42 & 1026.95 & 88.40 & 13.7 & 0.95 & 19.4 & $33.5 \%$ & $\mathrm{~d}-\mathrm{c}$ \\
$\mathrm{GG}^{*}$ & 1.80 & 418.22 & 36.00 & 23.0 & 1.51 & 42.8 & $13.6 \%$ & $\mathrm{c}-\mathrm{b}-\mathrm{e}$ \\
\hline
\end{tabular}

*The presented values in this row are the average of four valid test results 

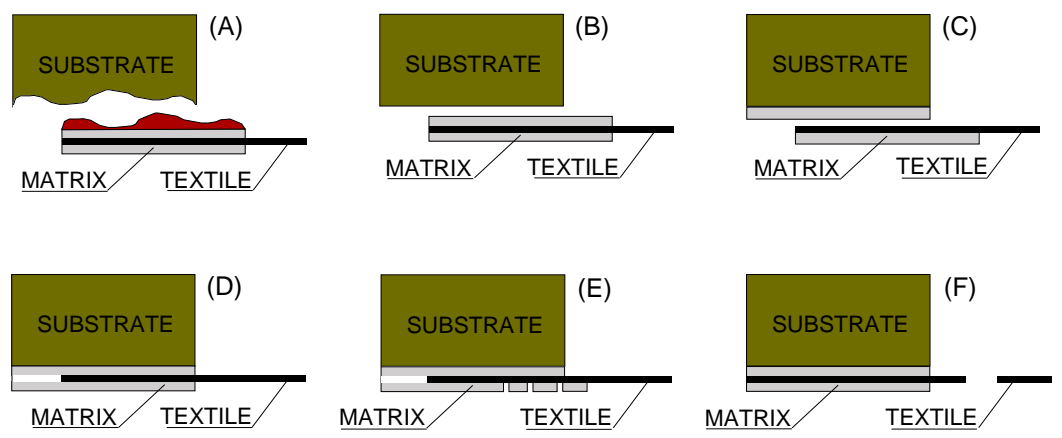

Fig. 10. Schematic presentation of the failure modes in shear bond tests.

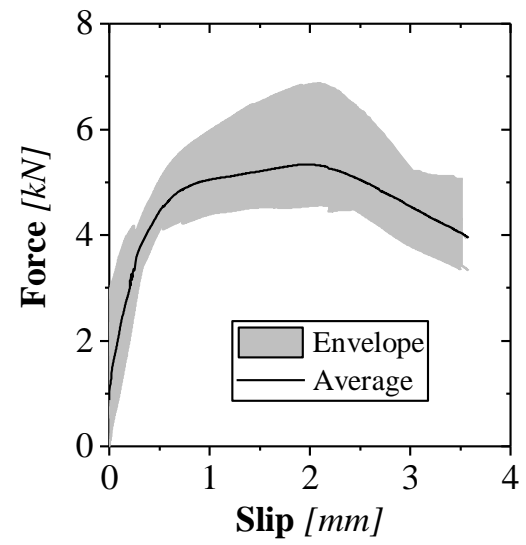

(a)

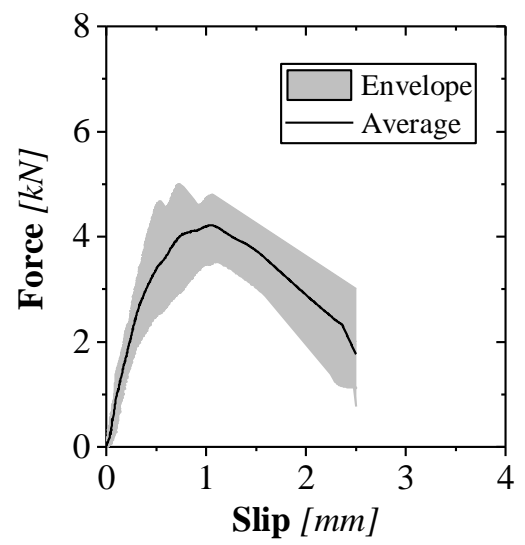

(b)

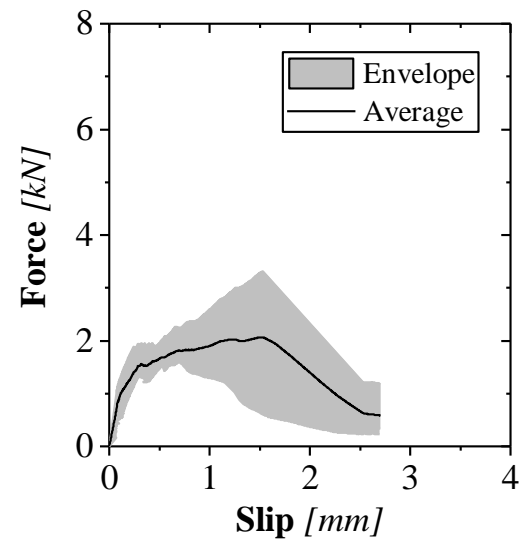

(c)

Fig. 11. Experimental force-slip curves of the strengthened specimens: (a) GA; (b) GB; (b) GG.

The GA reinforcement displayed a peak reinforcement stress $\left(\mathrm{f}_{\mathrm{b}}\right)$ of $1229.09 \mathrm{~N} / \mathrm{mm}^{2}(\mathrm{CV}=16.8 \%)$, corresponding to an exploitation ratio of $\eta_{\mathrm{s}}=40.0 \%$ and to a load per unit width of $105.8 \mathrm{kN} / \mathrm{m}$, see Table 4. No relation is observed between the bond strength in single-lap shear bond tests (GA specimens) and single fiber pull-out tests (SRGA specimens). It can be observed that the exploitation ratio in GA specimens is more than double than that of single fiber specimens (SRGA with $l_{\mathrm{b}}=150 \mathrm{~mm}$ ). Several factors can be the reason for this observation including: (1) a better bond performance in GA specimens because of the transverse plastic mesh; (2) possible imperfections in bond in SRGA specimens leading to a lower bond strength in those specimens; (3) although the specimens are cured for the same time and conditions, the size differences may lead to a different degree of curing and thus bond strength. However, a concrete conclusion can only be made if these 
tests are combined with a deep microstructural analysis and additional tests on the effect of transverse plastic mesh on the bond strength. These latter are out of the scope of this paper and are proposed for future studies.

The force-slip response, see Fig. 11(a), presents a relatively ductile behavior which is associated to the observed failure mode in GA specimens. The curve is composed of an initial stiff phase up to a slip of about $0.5 \mathrm{~mm}$ (in the average curve), followed by slippage of the textile out of matrix with a slight increase in resisting stress (the curves are basically horizontal). Finally, the stress decreases at a slip of about $2.0 \mathrm{~mm}$ corresponding to occurrence of slip at the free end of the specimens. It should be noted that the slip at peak $\left(\mathrm{s}_{\mathrm{p}}\right)$ of the average curve, Fig. 11(a), is (around $2 \mathrm{~mm})$ slightly different than the average of peak slips presented in Table $4(1.51 \mathrm{~mm})$. This difference has occurred due to the averaging method adopted for presenting the force-slip curves. The average peak slip in GA specimens is slightly lower than the single fiber pull-out tests ( $3 \mathrm{~mm}$ in SRGA with $\left.l_{\mathrm{b}}=150 \mathrm{~mm}\right)$.

The GB reinforcement displayed a peak reinforcement stress $\left(f_{b}\right)$ of $1026.95 \mathrm{~N} / \mathrm{mm}^{2}(\mathrm{CV}=13.7 \%)$ corresponding to an exploitation ratio of $\eta_{\mathrm{s}}=33.5 \%$ and to a load per unit width of $88.4 \mathrm{kN} / \mathrm{m}$, see Table 4. This value is slightly less than GA reinforcement. The failure mode was initially mode (d) followed by failure mode (c) near the end of the tests. The stress-slip response curve, see Fig. 11(b), presents a different shape in comparison to GA specimens, possibly, due to the activation of failure mode (c). The stress decreases in this case after reaching the peak stress (corresponding to a peak slip of $\left.s_{p}=0.95 \mathrm{~mm}\right)$. The peak stress in these specimens is much less than the peak stress developed in the single fiber specimens (SRGB with $l_{\mathrm{b}}=150 \mathrm{~mm}$ ) which is due to the different observed failure modes. In GB specimens, the early occurrence of mode (c) has led to a lower employment ratio of the fibers' capacity in comparison to SRGB specimens. 
The GG reinforcement had a peak reinforcement stress $\left(f_{b}\right)$ to of $418.22 \mathrm{~N} / \mathrm{mm}^{2}(\mathrm{CV}=23.0 \%)$ corresponding to an exploitation ratio of $\eta_{\mathrm{s}}=13.6 \%$ and to a load per unit width of $36.0 \mathrm{kN} / \mathrm{m}$, see Table 4. The shape of the force-slip response, see Fig. 11(c), is similar to GA specimens with a significantly lower peak stress but a similar slip at peak (around $1.8 \mathrm{~mm}$ ). The failure mode was a combination of modes $(\mathrm{c}, \mathrm{b}, \mathrm{e})$ showing that the bond performance between the mortar and the substrate was the weakest link in this system. Further investigations are thus necessary for improvement of the geopolymeric mortar-to-brick bond strength. Again, due to the different failure modes observed in GG and SRGG specimens (single fiber pull-out tests), the results are not comparable.

A combination of factors can affect the bond strength and the failure mode of these systems [1,2], including (i) the strength of the textile and the cord-to-mortar bond/interlocking, (ii) the mechanical properties of the mortar matrix, (iii) the roughness of the substrate, and (iv) the experimental setup and the manufacturing and curing conditions. As in the current study the only difference between the specimens is the mortar, the influencing factors are the matrix mechanical properties, fabric-to-mortar bond behavior, and curing kinetics of the mortars. The results indicate that the properties of the matrix can significantly affect the bond performance in SRG systems.

\section{Conclusions}

A multi-level experimental characterization of three steel reinforced grout (SRG) systems, made of two commercially available lime-based mortars and a geopolymeric-based mortar, was presented in this study. The following conclusions can be drawn from the observation and presented results: 
- $\quad$ Single-fiber pull-out tests showed that the matrix (mechanical, physical and chemical properties) can affect the effective bond length and the bond performance (force-slip curves, bond strength, etc.) in SRG systems. Single-sided pull-out test setup was found simple but with specific challenges such as slip measurements. Improvements in the measurement system when LVDTs are used (such as use of a resin block as reported in [27]) or use of advanced measurement techniques (such as feature tracking method [28]) should thus be considered. Future studies on pull-out behavior of fabrics embedded in mortar and on the effect of transverse fibers on the bond performance are necessary for development of suitable constitutive models.

- $\quad$ Tensile tests showed the tensile response of SRGs is mainly governed by the fibers properties (with an average stiffness of around $70 \%$ of the dry fibers stiffness). The tension stiffening behavior and cracking of the mortar was also observed to be dependent on the mortar mechanical properties and the fiber-to-mortar bond behavior. Direct application of the gripping system on dry textile fibers with the aim of aluminum plates was found to be advantageous in comparison to other application methods. In this system: (i) the slippage of fibers from the gripping area is completely avoided; (ii) the applied stresses can be directly and accurately calculated and (iii) the results provide the average response of embedded fibers which can be used for calculation of the tension stiffening effects.

- $\quad$ Single-lap shear bond tests showed the TRM-to-brick bond behavior can be significantly affected by the mortar properties and mortar-to-masonry bond strength. The bond strength, failure mode and force-slip curves varied widely with mortar type.

- $\quad$ No specific correlation was found between the results obtained from single fiber-to-mortar bond tests and TRM-to-brick bond tests. This can be due to several factors including the effect of 
transverse plastic mesh as well as the differences in mortar thickness, boundary conditions and curing degree.

\section{Acknowledgements}

The first author acknowledges the financial support of the Ministério da Ciência, Tecnologia e Ensino Superior, FCT, Portugal, under the grant SFRH/BPD/92614/2013.

\section{References}

[1] de Felice G, De Santis S, Garmendia L, et al. Mortar-based systems for externally bonded strengthening of masonry. Mater Struct 2014;47:2021-37. doi:10.1617/s11527-014-03601.

[2] Brameshuber W (ed). Textile reinforced concrete. State-of-the-Art Report of RILEM Technical Commitee 201-TRC. RILEM Report 36, 2006, RILEM Publications S.A.R.L.

[3] Triantafillou TC, Papanicolaou CG. Textile Reinforced Mortars (TRM) versus Fiber Reinforced Polymers ( FRP) as strengthening materials of concrete structures. FRPRCS-7, Kansas City, Missouri: 2005, p. 99-118.

[4] Ascione L, de Felice G, De Santis S. A qualification method for externally bonded Fiber Reinforced Cementitious Matrix (FRCM) strengthening systems. Compos Part B Eng 2015. doi:10.1016/j.compositesb.2015.03.079.

[5] Garmendia L, Larrinaga P, San-Mateos R, San-Jose JT. Strengthening masonry vaults with organic and inorganic composites: An experimental approach. Mater Des 2015;85:102-14. doi:10.1016/j.matdes.2015.06.150.

[6] Babaeidarabad S, Arboleda D, Loreto G, Nanni A. Shear strengthening of un-reinforced concrete masonry walls with fabric-reinforced-cementitious-matrix. Constr Build Mater 2014;65:243-53. doi:10.1016/j.conbuildmat.2014.04.116.

[7] Parisi F, Iovinella I, Balsamo A, et al. In-plane behavior of tuff masonry strengthened with inorganic matrix-grid composites. Compos Part B Eng 2013;45:1657-66. doi:10.1016/j.compositesb.2012.09.068.

[8] Carozzi FG, Milani G, Poggi C. Mechanical properties and numerical modeling of Fabric Reinforced Cementitious Matrix (FRCM) systems for strengthening of masonry structures. Compos Struct 2014;107:711-25. doi:10.1016/j.compstruct.2013.08.026.

[9] Larrinaga P, Chastre C, Biscaia HC, San-José JT. Experimental and numerical modeling of basalt textile reinforced mortar behavior under uniaxial tensile stress. Mater Des 2014;55:66-74. doi:10.1016/j.matdes.2013.09.050.

[10] De Santis S, de Felice G. Steel reinforced grout systems for the strengthening of masonry structures. Compos Struct 2015;134:533-48. doi:10.1016/j.compstruct.2015.08.094.

[11] Borri A, Castori G, Corradi M. Shear behavior of masonry panels strengthened by high strength steel cords. Constr Build Mater 2011;25:494-503. 
doi:10.1016/j.conbuildmat.2010.05.014.

[12] Borri A, Casadei P, Castori G, Hammond J. Strengthening of brick masonry arches with externally bonded steel reinforced composites. J Compos Constr 2009;13:468-75. doi:10.1061/(ASCE)CC.1943-5614.0000030.

[13] De Santis S, Casadei P, De Canio G, et al. Seismic performance of masonry walls retrofitted with steel reinforced grout. Earthq Eng Struct Dyn 2016;45:229-51. doi:10.1002/eqe.2625.

[14] Razavizadeh A, Ghiassi B, Oliveira DV. Bond behavior of SRG-strengthened masonry units: Testing and numerical modeling. Constr Build Mater 2014;64:387-97. doi:10.1016/j.conbuildmat.2014.04.070.

[15] European Norm EN 1015-11. Methods of test mortar for masonry Part 11: Determination of flexural and compressive strength of hardened mortar, 2007.

[16] EN 772-1. Methods of test for masonry units. Determination of compressive strength, 2011.

[17] Vejmelková E, Keppert M, Keršner Z, Rovnaníková P, Černý R. Mechanical, fracturemechanical, hydric, thermal, and durability properties of lime-metakaolin plasters for renovation of historical buildings. Constr Build Mater 2012;31:22-8. doi:10.1016/j.conbuildmat.2011.12.084.

[18] Lanas J, Sirera R, Alvarez J. Study of the mechanical behavior of masonry repair lime-based mortars cured and exposed under different conditions. Cem Concr Res 2006;36:961-70. doi:10.1016/j.cemconres.2005.12.003.

[19] Pavlík V, Užáková M. Effect of curing conditions on the properties of lime, limemetakaolin and lime-zeolite mortars. Constr Build Mater 2016;102:14-25. doi:10.1016/j.conbuildmat.2015.10.128.

[20] Lanas J, Bernal JLP, Bello M, Galindo JI. Mechanical properties of natural hydraulic limebased mortars. Cem Concr Res 2004;34:2191-201. doi:10.1016/j.cemconres.2004.02.005.

[21] Gray RJ. Experimental techniques for measuring fibre/matrix interfacial bond shear strength. Int J Adhes Adhes 1983;3:197-202. doi:10.1016/0143-7496(83)90094-5.

[22] Li VC, Chan Y. Determination of interfacial debond mode for fiber-reinforced cementitious composites. J Eng Mech 1994;120:707-19. doi:10.1061/(ASCE)07339399(1994)120:4(707).

[23] Bentur A, Wu ST, Banthia N, et al. Fiber-Matrix Interfaces. In High Performance Fiber Reinforced Cement Composites 2, edited by A.E. Naaman and H.W. Reinhardt. 1996, London, UK: E \& FN SPON.

[24] Francis D, Ward C, DiFrancia C, et al. The single-fibre pull-out test. 1: Review and interpretation. Compos Part A Appl Sci Manuf 1996;27:597-612. doi:10.1016/1359835X(95)00069-E.

[25] Zhandarov S, Mäder E. Characterization of fiber/matrix interface strength: Applicability of different tests, approaches and parameters. Compos Sci Technol 2005;65:149-60. doi:10.1016/j.compscitech.2004.07.003.

[26] Lorenz E, Ortlepp R. Bond behavior of textile reinforcements - Development of a pull-out test and modeling of the respective bond versus slip relation. in RILEM Bookseries. High Perform. fiber Reinf. Cem. Compos. 6., vol. 2, Springer; 2012, p. 479-86. doi:10.1007/97894-007-2436-5_58.

[27] Banholzer B. Bond of a strand in a cementitious matrix. Mater Struct 2006;39:1015-28. doi:10.1617/s11527-006-9115-y.

[28] Ghiassi B, Xavier J, Oliveira DV, Lourenço PB. Application of digital image correlation in investigating the bond between FRP and masonry. Compos Struct 2013;106:340-9. 
doi:10.1016/j.compstruct.2013.06.024.

[29] Hartig J, Jesse F, Schicktanz K, Häußler-Combe U. Influence of experimental setups on the apparent uniaxial tensile load-bearing capacity of textile reinforced concrete specimens. Mater Struct 2011;45:433-46. doi:10.1617/s11527-011-9775-0.

[30] Yue CY, Looi HC, Quek MY. Assessment of fibre-matrix adhesion and interfacial properties using the pull-out test. Int J Adhes Adhes 1995;15:73-80. doi:10.1016/01437496(95)98740-D.

[31] Hutchinson JW, Jensen HM. Models of fiber debonding and pullout in brittle composites with friction. Mech Mater 1990;9:139-63. doi:10.1016/0167-6636(90)90037-G.

[32] Naaman AE, Namur G, Najm H, Alwan J. Bond mechanisms in fiber reinforced cementbased composites. Report No. UMCE 89-9, 1989, University of Michigan.

[33] Mobasher B, Li CY. Modeling of stiffness degradation of the interfacial zone during fiber debonding. Compos Eng 1995;5:1349-65. doi:10.1016/0961-9526(95)00056-S.

[34] Holler S, Butenweg C, Noh SY, Meskouris K. Computational model of textile-reinforced concrete structures. Comput Struct 2004;82:1971-9. doi:10.1016/j.compstmc.2004.03.076.

[35] Mobasher B, Pahilajani J, Peled A. Analytical simulation of tensile response of fabric reinforced cement based composites. Cem Concr Compos 2006;28:77-89. doi:10.1016/j.cemconcomp.2005.06.007.

[36] Hartig J, Häußler-Combe U, Schicktanz K. Influence of bond properties on the tensile behavior of textile reinforced concrete. Cem Concr Compos 2008;30:898-906. doi:10.1016/j.cemconcomp.2008.08.004.

[37] Mobasher B. Mechanics of Fiber and Textile Reinforced Cement Composites. 2012, New York, Taylor and Francis Group, CRC Press.

[38] Soranakom C, Mobasher B. Modeling of tension stiffening in reinforced cement composites: Part I. Theoretical modeling. Mater Struct 2010;43:1217-30. doi:10.1617/s11527-010-9594-8. 


\section{List of Tables}

Table 1. Mechanical properties of brick and mortars (CV in round brackets).

Table 2. Results of single fiber pull-out tests on SRG systems*.

Table 3. Results of direct tensile tests on SRG systems*.

Table 4. Results of single-lap shear bond tests on SRG systems.

\section{List of Figures}

Fig. 1. Experimental setups for materials' mechanical characterization: (a) compressive test on brick; (b) compressive test on mortar; (c) flexural test on mortar; (d) direct tensile test on steel fabric.

Fig. 2. (a) Specimens prepared for pull-out tests; (b) geometrical details of the specimens; (c) test setup.

Fig. 3. (a) Geometrical details of fiber reinforced mortar specimens; (b) experimental setup for tensile characterization of SRG composites.

Fig. 4. (a) Specimens prepared for single-lap pull out tests; (b) geometrical details of the specimens; (c) single-lap shear bond test setup.

Fig. 5. Experimental force-slip curves for SRGA system: (a) $l_{\mathrm{b}}=100 \mathrm{~mm}$; (b) $l_{\mathrm{b}}=150 \mathrm{~mm}$; (c) $l_{\mathrm{b}}=200 \mathrm{~mm}$; (d) $l_{\mathrm{b}}=250 \mathrm{~mm}$.

Fig. 6. Experimental force-slip curves for SRGB system: (a) $l_{\mathrm{b}}=100 \mathrm{~mm}$; (b) $l_{\mathrm{b}}=150 \mathrm{~mm}$; (c) $l_{\mathrm{b}}=200 \mathrm{~mm}$.

Fig. 7. Experimental force-slip curves for SRGG system: (a) $l_{\mathrm{b}}=100 \mathrm{~mm}$; (b) $l_{\mathrm{b}}=150 \mathrm{~mm}$; (c) $l_{\mathrm{b}}=200 \mathrm{~mm}$; (d) $l_{\mathrm{b}}=250 \mathrm{~mm}$.

Fig. 8. Average force-slip curves for: (a) SRGA; (b) SRGB; (c) SRGG.

Fig. 9. Experimental tensile response of tested SRG systems: (a) SRGA; (b) SRGB; (c) SRGG.

Fig. 10. Schematic presentation of the failure modes in shear bond tests.

Fig. 11. Experimental force-slip curves of the strengthened specimens: (a) GA; (b) GB; (b) GG. 